\title{
The Effect of Lipophilic Weak Acids on the Segregational Stability of TOL Plasmids in Pseudomonas putida
}

\author{
By GILLIAN M. STEPHENS* AND HOWARD DALTON \\ Department of Biological Sciences, University of Warwick, Coventry CV4 7AL, UK
}

(Received 7 November 1986; revised 23 February 1987)

\begin{abstract}
The effect of various lipophilic weak acids on the stability of certain TOL plasmids was investigated. Benzoate induced deletion of TOL plasmid DNA in Pseudomonas putida MT15, followed by loss of the plasmid; this effect was $\mathrm{pH}$ - and concentration-dependent, suggesting that undissociated benzoic acid was a more effective curing agent than the benzoate anion. Plasmid loss always approached a frequency of $100 \%$ after a lag and apparently depended on the prior occurrence of deletions, although deleted plasmid was stably maintained in the absence of the acid. $m$-Toluate, acetate and butyrate also induced deletions and plasmid loss at high frequencies, although these acids were less effective than benzoate. Benzoate inhibited the growth of plasmid-containing cells rather than permitting faster growth of cured cells on benzoate. Similar results were obtained with $P$. putida strains MT20 and MT84, which contain different TOL plasmids. We suggest that lipophilic weak acids induced deletions, possibly by excision of a transposon-like region, and disrupted the segregation of deleted plasmid.
\end{abstract}

\section{INTRODUCTION}

Catabolic plasmids encoding the degradation of various aromatic compounds and $n$-alkanes have been found in several strains of Pseudomonas putida. It is well known that plasmids encoding $m$-toluic acid or naphthalene degradation are cured or undergo large, plasmid-specific deletions at high frequencies if the host strain is grown on benzoic acid (Nakazawa \& Yokota, 1973; Williams \& Murray, 1974; Bayley et al., 1977; Kunz \& Chapman, 1981; Pickup \& Williams, 1982; Pickup et al., 1983; Clarke \& Laverack, 1984; Keil \& Williams, 1985). These strains possess both plasmid- and chromosomally-encoded pathways for benzoate degradation. The meta-cleavage pathway, which is plasmid-borne, is induced by benzoate whilst the 'chromosomal' ortho-cleavage pathway is induced by cis,cis-muconate (Fig. 1). Plasmid-bearing strains degrade benzoate by the meta-cleavage pathway because insufficient inducer of the ortho-cleavage pathway accumulates; however, cured strains grow more rapidly on benzoate because the ortho-cleavage pathway permits more 'efficient' utilization of benzoate (Nakazawa \& Yokota, 1973; Williams \& Murray, 1974). It has therefore been suggested that benzoate is efficient as a curing agent because plasmid-free cells grow more rapidly on benzoate than plasmid-bearing cells. However, recent studies on the kinetics of benzoate-induced plasmid loss suggest that this explanation is incorrect and that benzoate probably disrupts plasmid partitioning (Keshavarz et al., 1985).

The mechanism of plasmid partitioning is poorly understood and it is certainly not possible at present to postulate a mechanism by which benzoate might disrupt plasmid partitioning in Pseudomonas. The ability of benzoate to induce large, plasmid-specific deletions in TOL plasmids (e.g. Keil \& Williams, 1985) is even less well understood. However, an understanding of these phenomena might be approached if other compounds having a similar effect could be

Abbreviations: C230, catechol 2,3-oxygenase; C12O, catechol 1,2-oxygenase. 
(a)<smiles>[R]c1ccc(CCCCC)cc1[R]</smiles><smiles>[R]c1ccc(C(=O)O)cc1[R]</smiles><smiles>[R]c1ccc(O)c(O)c1[R]</smiles><smiles>[R]C(=O)/C=C\C(O)=C(\[R])O</smiles>

(h)<smiles>[R]c1cccc(C(=O)O)c1</smiles>

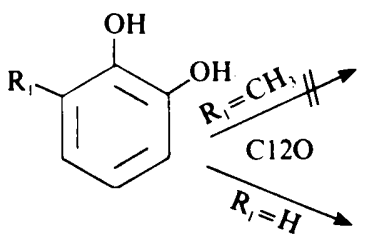<smiles>O=C(O)c1ccccc1</smiles>

Fig. 1. (a) Plasmid-encoded and $(b)$ chromosomally-encoded pathways for the degradation of aromatic compounds in $P$. putida. $m$-Xylene $\left(\mathbf{R}_{1}=\mathrm{CH}_{3}, \mathbf{R}_{2}=\mathrm{H}\right)$, p-xylene $\left(\mathbf{R}_{1}=\mathrm{H}, \mathbf{R}_{2}=\mathrm{CH}_{3}\right)$ and toluene $\left(\mathrm{R}_{1}\right.$ and $\left.R_{2}=H\right)$ are degraded by plasmid-encoded enzymes. Benzoate $\left(R_{1}=H\right)$ and $m$-toluate $\left(R_{1}=C_{3}\right)$ are normally degraded by the plasmid-encoded enzymes but if the plasmid is lost, chromosomallyencoded enzymes effect the complete degradation of benzoate and partial metabolism of $m$-toluate.

identified. Such compounds might have a structural or functional similarity to benzoate. $m$-Toluate is a structural analogue of benzoate and is also degraded via TOL-plasmid-coded enzymes. Benzoate and $m$-toluate are lipophilic weak acids, as are acetate and butyrate, although the latter compounds are non-aromatic. We describe here the effect of these acids on TOL plasmid stability.

\section{METHODS}

Organisms. Pseudomonas putida strains MT15 (pWW15), MT20 (pWW20) and MT84 (pWW84) were obtained from P. A. Williams, University College of North Wales, Bangor, UK, and all carry TOL plasmids. The strains were maintained on L-agar. The phenotypic properties of derivatives of these strains are summarized in Table 1.

Curing experiments. Organisms were grown as flask cultures in MS medium (pH 6.8 or 6.2) which contained $\mathrm{KH}_{2} \mathrm{PO}_{4}, 2 \mathrm{~g} \mathrm{l}^{-1} ; \mathrm{NH}_{4} \mathrm{Cl}, 3 \mathrm{~g} \mathrm{I}^{-1} ; \mathrm{MgSO}_{4} .7 \mathrm{H}_{2} \mathrm{O}, 0.4 \mathrm{~g} \mathrm{l}^{-1}$; and trace elements solution [Vishniac \& Santer (1957), but containing only $\left.0 \cdot 22 \% \mathrm{ZnSO}_{4} \cdot 7 \mathrm{H}_{2} \mathrm{O}\right], 2 \mathrm{ml} \mathrm{l}^{-1}$. Sodium gluconate $\left(5 \mathrm{~g} \mathrm{l}^{-1}\right)$ was added as the carbon and energy source and lipophilic weak acids (sodium or potassium salt) were added as required. $\mathrm{NaCl}$ and $\mathrm{KCl}$ did not affect plasmid stability. Cultures were grown at $30^{\circ} \mathrm{C}$ for 6-8 generations to a density of $5 \times 10^{9}-1 \times 10^{10}$ cells ml $^{-1}$, sampled for the determination of deletion and plasmid loss frequencies and subcultured. Experiments were continued for up to 60 generations or until plasmid loss occurred.

Determination of deletion and plasmid loss frequencies. Cells containing intact plasmid express catechol 2,3oxygenase (C23O) activity after growth in the presence of either $m$-toluate or toluene; deletants do not express $\mathrm{C} 23 \mathrm{O}$ after growth with $\boldsymbol{m}$-toluate whilst plasmid-free cells show no activity after growth in the presence of either substrate (Keil \& Williams, 1985). Diluted samples of cultures were spread on pyruvate $\left(5 \mathrm{~g}^{-1}\right) \mathrm{MS}^{2}$ agar with and without $m$-toluate $\left(0.2 \mathrm{~g} \mathrm{l}^{-1}\right)$; the latter cultures were incubated under toluene vapour. The resulting colonies (at least 200 per sample) were sprayed with $0.1 \mathrm{M}$-catechol and $\mathrm{C} 23 \mathrm{O}$ activity was inferred to be present when the colonies turned yellow due to the formation of 2-hydroxymuconic semialdehyde. Frequencies of plasmid loss were calculated as being equal to the number of white colonies divided by the total number of colonies after growth with toluene. Subtraction of this frequency from the frequency of white colonies after growth with $m$-toluate gave the frequency of deletants. The validity of the method was confirmed by screening for growth on $m$-toluate and toluene and examining plasmid content by the method of Wheatcroft \& Williams (1981).

We do not distinguish between the two types of deletant which can arise from strain MT15 (Keil \& Williams, 1985). It is not possible to determine their relative frequencies on a routine, statistically appropriate basis in view . 
Table 1. Phenotypes of strains used

$\begin{array}{lccccc}\text { Strain } & \text { Plasmid } & \overbrace{m \text {-Xylene }} \text { Toluene } & m \text {-Toluate } & \text { Benzoate } \\ \text { MT15 } & + & + & + & + & + \\ \text { DMT15 } & +(D) & + & + & - & + \\ \text { CMT15 } & - & - & - & - & +(\mathrm{C} 120) \\ \text { MT20 } & + & + & - & + & + \\ \text { CMT20 } & - & + & + & + & + \\ \text { MT84 } & + & - & - & - & +\end{array}$

Abbreviations: + , growth; - , no growth (except where indicating presence or absence of the plasmid). D denotes plasmid carrying a deletion. $\mathrm{C} 12 \mathrm{O}$ indicates that benzoate was degraded via the catechol-1,2-oxygenase.

of their rather similar phenotypes and the need to analyse the plasmids using restriction enzymes to be certain of identifying each class of deletant.

Calculation of theoretical frequencies of plasmid-free cells after growth with $3 \mathrm{mM}$-benzoate. The growth rates $(\mu)$ of strains MT15 and CMT15 on gluconate in the presence of $3 \mathrm{~mm}$-benzoate were $0.336 \mathrm{~h}^{-1}$ and $0.525 \mathrm{~h}^{-1}$ respectively (Table 2). If the initial number of plasmid-free cells was $X_{0}^{F}$ and that of plasmid-containing cells was $X_{0}^{p}$, then the number of each type of cell after time $t\left(X_{t}^{\mp}\right.$ or $\left.X_{t}^{\mathrm{p}}\right)$ can be calculated by

$$
X_{t}^{(\mathrm{PorF})}=X_{0}^{(\mathrm{P} \text { or F) }} \mathrm{e}^{\mu}
$$

The frequency of plasmid-free cells $(F)$ is given by

$$
F=\frac{X_{t}^{\mathrm{F}}}{X_{t}^{\mathrm{F}}+X_{t}^{\mathrm{P}}}
$$

The total number of doublings of both types of cell $(n)$ after time $t$ is given by

$$
n=\frac{1}{\ln 2} \cdot \ln \left(\frac{X_{t}^{\mathrm{F}}+X_{t}^{\mathrm{P}}}{X_{0}^{\mathrm{F}}+X_{0}^{\mathrm{p}}}\right)
$$

See Pirt (1975) for the derivation of these equations.

\section{RESULTS}

Characterization of benzoate-induced plasmid loss. The TOL plasmid in $P$. putida MT15 was stably maintained over 50-60 generations when the organism was grown on gluconate in the absence of benzoate at either $\mathrm{pH} 6.8$ or $\mathrm{pH} 6.2$. However, plasmid loss was always observed when benzoate was added to the growth medium (Fig. 2). Plasmid loss occurred after a lag, the length of which depended upon the concentration of benzoate. Plasmid loss was more rapid at pH 6.2 (Fig. $2 b$ ), suggesting that undissociated benzoic acid was a more efficient curing agent.

Dependence of plasmid loss upon the occurrence of deletions. Deletions always occurred before any plasmid loss was observed. At lower benzoate concentrations (1-3 mM) there was a lag before the appearance of deletants and the frequency of deletants approached $100 \%$ before plasmid loss occurred. This suggested that plasmid loss was dependent on the prior occurrence of deletions. We therefore compared the rates of plasmid loss from strains MT15 (wild-type plasmid) and DMT15 (plasmid carrying a deletion) when exposed to benzoate. Plasmid loss approached $100 \%$ approximately 13 generations earlier in strain DMT15 than in strain MT15 (Fig. 3). This indicated that deletions caused instability of the plasmid. However, deleted plasmid was not lost from strain DMT15 in the absence of benzoate and, if DMT15 was grown on gluconate alone, revertant organisms were selected which expressed $\mathrm{C} 23 \mathrm{O}$ activity after growth with $m$-toluate. We therefore conclude that benzoate caused instability of the deleted plasmid. The reversion of TOL deletions has been explained by Keil et al. (1985), who demonstrated that the plasmid from strain MT15 contains two C23O genes. One of these (C23OI) is lost after deletion of plasmid DNA and the remaining C23OII is induced by $m$-xylene 


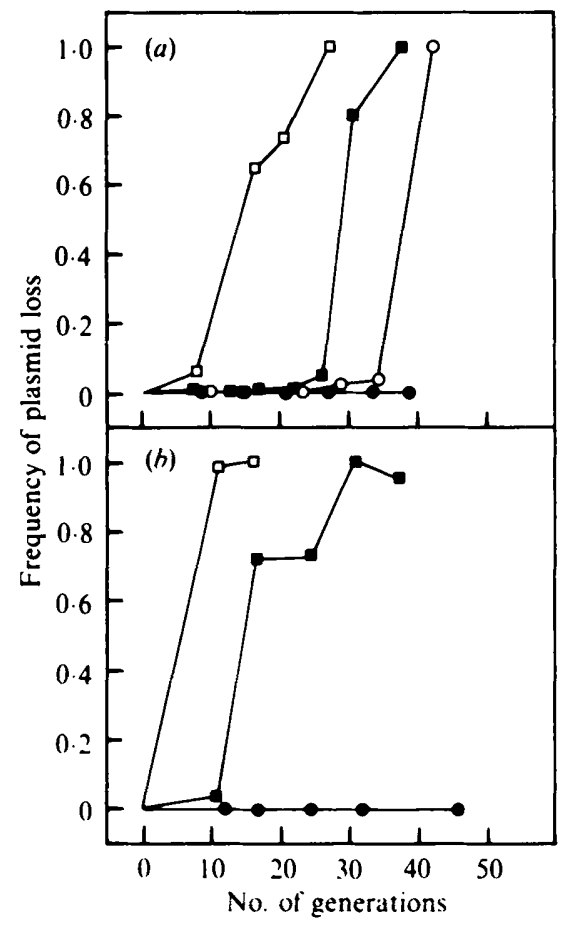

Fig. 2

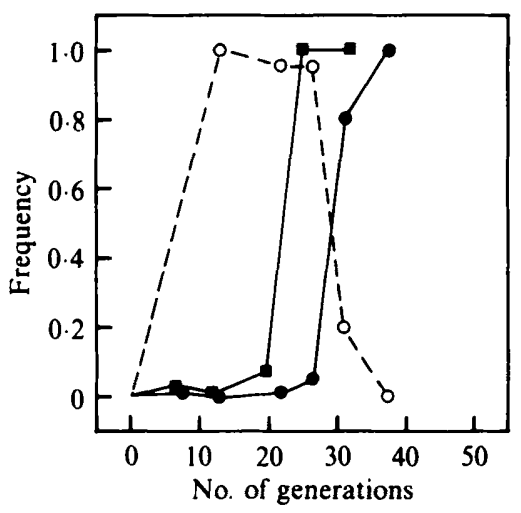

Fig. 3

Fig. 2. Concentration dependence of benzoate-induced plasmid loss from $P$. putida MT15 at pH 6.8 (a) and pH 6.2 (b). No benzoate; $\bigcirc, 1$ mM-benzoate; $\square, 3$ mM-benzoate, $\square, 6$ mM-benzoate.

Fig. 3. Effect of plasmid deletions on the rate of plasmid loss in P putida MT15. Plasmid loss was induced by the addition of $3 \mathrm{~mm}$-benzoate. $O$, Frequency of deletions of plasmid from strain MT15; $P$, $\square$, frequency of plasmid loss from strain MT15 (O) and deletant strain DMT15 ( $\square$ ).

(and presumably toluene) but not $m$-toluate. Reversion to growth on $m$-toluate is thought to result from tandem amplification of the C23OII gene, leading to constitutive expression of C23OII (Keil \& Williams, 1985; Keil et al., 1985).

$m$-Toluate-induced plasmid loss. The TOL plasmid encodes the ability to degrade $m$-toluic acid, which is a structural analogue of benzoic acid and a lipophilic weak acid. We found that $m$ toluate also induced plasmid loss during growth on gluconate after a lag during which plasmid deletions occurred (Fig. 4). The rate of plasmid loss depended upon the concentration of $m$ toluate but $m$-toluate was a less efficient curing agent than benzoate.

Cultures which had lost the TOL plasmid turned black after growth in the presence of $\mathrm{m}$ toluate. Several intermediates of $m$-toluate catabolism are unstable and form black oxidation products. Benzoate-grown, plasmid-free cells oxidized $m$-toluate (results not shown), suggesting that chromosomally-encoded enzymes catalysed the partial oxidation of $m$-toluate. However, $m$ toluate did not support the growth of plasmid-free cells.

Plasmid loss induced by aliphatic weak acids. Acetate and butyrate also induced plasmid loss (Fig. 5) but the results were less reproducible than with benzoate or $m$-toluate. On some occasions, plasmid loss was very rapid (approximately 20 generations) and on others, low levels of loss occurred after approximately $\mathbf{4 0}$ generations. These acids therefore induced plasmid loss and we discuss later some reasons why the rate of loss was not reproducible. 


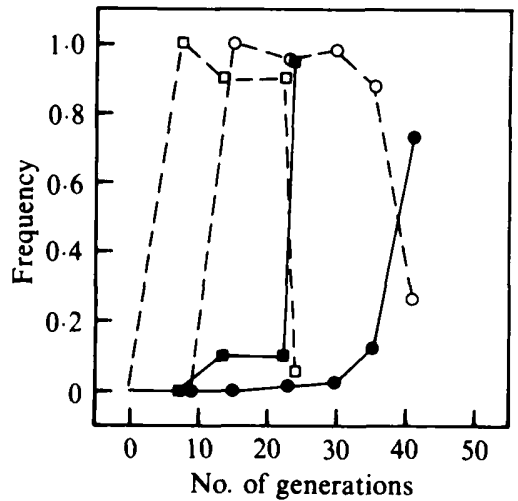

Fig. 4

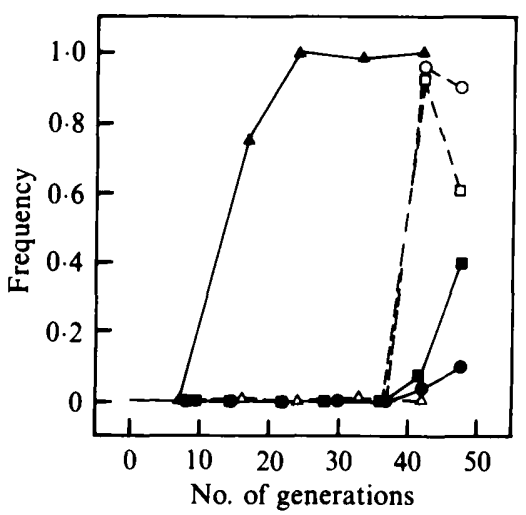

Fig. 5

Fig. 4. $m$-Toluate-induced plasmid loss from $P$. putida MT15. The rate of plasmid loss was compared during exposure to 5 or $10 \mathrm{~mm}-m$-toluate. , F , Frequency of plasmid loss with $5 \mathrm{~mm}(\mathrm{O})$ and $10 \mathrm{mM}$ ( $\square$ ) -toluate; $O, \square$, frequency of deletants with $5 \mathrm{~mm}(O)$ and $10 \mathrm{~mm}(\square) m$-toluate.

Fig. 5. Acetate- and butyrate-induced plasmid loss from $P$. putida MT15. Plasmid loss was monitored during exposure to acetate $(10 \mathrm{mM})$ or butyrate $(10 \mathrm{mM})$. The results of two experiments with $10 \mathrm{mM}$ acetate are shown. $\square, O, \Delta$, Frequency of plasmid loss after exposure to butyrate $(\square)$ and after exposure to acetate, $(O$, experiment $1 ; \Delta$, experiment 2$) . \square, O, \triangle$, Frequency of deletants after exposure to butyrate $(\square)$ and after exposure to acetate $(O$, experiment $1 ; \triangle$, experiment 2 ).

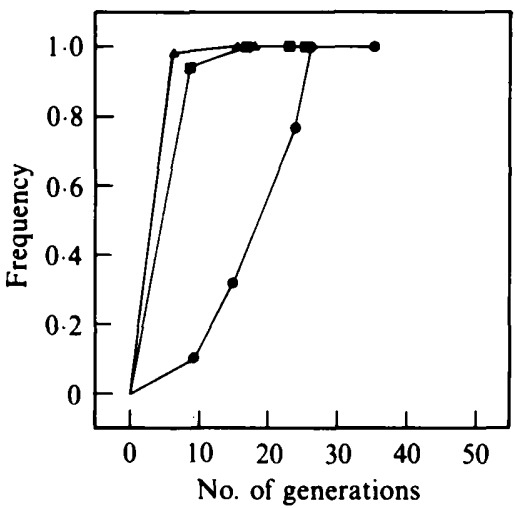

Fig. 6. Benzoate-induced plasmid loss in P. putida MT20. , 3 mm-benzoate; $\square, 6$ mM-benzoate; $\Delta$, 9 mM-benzoate. For clarity, plasmid loss frequencies but not deletion frequencies are shown.

Effect of lipophilic weak acids on the stability of TOL plasmids in other strains of P. putida. Benzoate-induced plasmid loss was more rapid in P. putida MT20 than in strain MT15 (Fig. 6). $m$-Toluate also induced plasmid loss in strains MT20 and MT84, but acetate was ineffective in strain MT20. The rate of acetate-induced plasmid loss in MT84 varied between experiments as was noted also in strain MT15.

Effect of benzoate on the growth rate. It has been suggested that plasmid-free cells out-compete plasmid-containing cells during growth on benzoate because they grow more rapidly (Williams \& Murray, 1974). We examined the growth rate of plasmid-containing and plasmid-free strains under various growth conditions (Table 2). There was no significant difference in the rate of growth on gluconate but MT20 grew very slowly on benzoate compared with CMT20 (lacking plasmid), which confirms previous findings. However, growth of strain MT20 on gluconate in 
Table 2. Effect of plasmid loss or deletions on the growth of $P$. putida strains

Growth rates were determined from the increase in $\mathrm{OD}_{540}$ during growth on $0.5 \%$ gluconate, $0.5 \%$ gluconate plus $3 \mathrm{~mm}$-benzoate or $1.3 \mathrm{~mm}$-benzoate. Deletions and plasmid loss did not occur over the course of these experiments.

\begin{tabular}{lccc} 
& \multicolumn{3}{c}{ Growth rate $\left(\mathrm{h}^{-1}\right)$ on: } \\
\cline { 2 - 4 } Strain & Gluconate & Gluconate + benzoate & Benzoate \\
MT20 & 0.608 & 0.26 & 0.138 \\
CMT20 & 0.611 & 0.576 & 0.458 \\
MT15 & 0.506 & 0.336 & ND \\
DMT15 & 0.545 & 0.314 & ND \\
CMT15 & 0.552 & 0.525 & ND
\end{tabular}

ND, Not determined.

the presence of benzoate was slower than that of CMT20, suggesting that benzoate inhibited the growth of plasmid-containing cells. Similar results were obtained with strain MT15. Interestingly, plasmid deletions did not result in a growth rate advantage since the growth of strain DMT15 was also inhibited by benzoate.

Reproducibility of results. Growth in the presence of the lipophilic weak acids tested resulted in plasmid loss but the lag before plasmid loss occurred was variable. Benzoate-induced plasmid loss was faster from cultures which had been derived from old cultures grown on L-agar plates than freshly grown cultures. Although we always used freshly grown cultures as the source of inoculum, it is extremely difficult to reproduce the physiological status of cultures grown on solid media and this may account for the variation in results. Experiments with benzoate generally gave reproducible results, which may reflect the greater effectiveness of this acid as an inducer of plasmid loss. In the case of comparative experiments, the cultures were grown from the same inoculum.

\section{DISCUSSION}

Benzoate, $m$-toluate, acetate and butyrate induced deletion of TOL plasmid DNA followed by loss of the plasmid. The dependence of plasmid loss on the prior occurrence of deletions has not previously been reported. Williams \& Murray (1974) suggested that benzoate curing was a result of the more efficient utilization of benzoate by plasmid-free cells, which therefore overgrew plasmid-containing cells. Our results suggest that this explanation is too simplistic since $m$ toluate, acetate and butyrate also induced plasmid loss. Plasmid-free cells cannot grow on $\mathrm{m}$ toluate and thus would obtain no growth advantage whilst acetate and butyrate metabolism is not encoded by the TOL plasmid. Indeed, our results suggest that plasmid loss is more likely to be associated with growth inhibition by these acids since benzoate inhibited growth on gluconate. Furthermore, it is unlikely that a metabolite of the acids caused plasmid loss since aliphatic and aromatic weak acids are metabolized by different pathways.

Large, plasmid-specific deletions of DNA from a variety of TOL plasmids have been reported (Bayley et al., 1977; Pickup \& Williams, 1982; Keil \& Williams, 1985). The archetypal TOL plasmid, pWW0, contains a $40 \mathrm{~kb}$ transposon-like region, flanked by $1.4 \mathrm{~kb}$ direct repeats. The catabolic genes are located within this region, which excises under benzoate selection, resulting in a deletion (Meulien et al., 1981). The TOL plasmid pWW15 is larger than pWW0 and benzoate selection results in the deletion of $90 \mathrm{~kb}$ segments of DNA from either of two regions of the TOL plasmid (Keil \& Williams, 1985). These deletions result in the loss of only some of the catabolic genes so that deletants retain the ability to grow on $m$-xylene but not on $m$-toluate (Keil et al., 1985). Whilst the phenotypic results of deletions of pWW0 and pWW15 under benzoate selection are rather different, it is possible that $\mathrm{pWW} 15$ and $\mathrm{pWW} 0$ deletions occur by a similar mechanism, i.e. excision by recombination between directly repeated sequences. Further investigation of the regions which excise from $\mathrm{pWW} 15$ should demonstrate whether this 


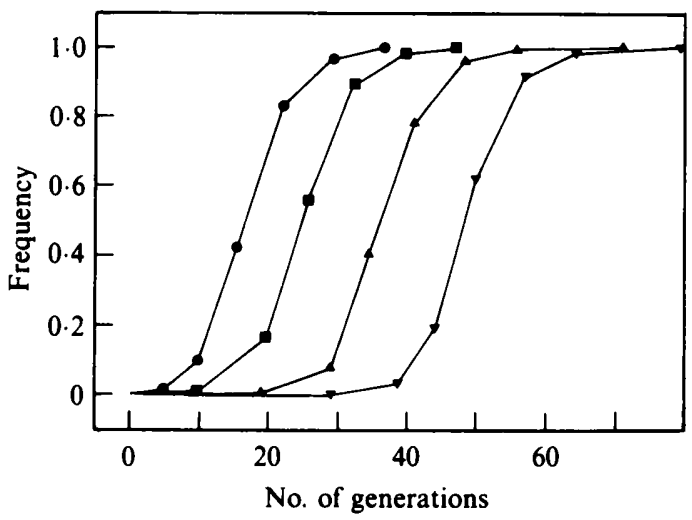

Fig. 7. Theoretical curves for plasmid loss in the presence of $3 \mathrm{~mm}$-benzoate. Assuming that a proportion of plasmid-free cells exists in the initial inoculum and that benzoate permits these cells to overgrow the plasmid-containing cells without affecting plasmid segregation, it is possible to calculate the frequency of plasmid-containing cells as growth continues. The curves show the frequencies of plasmid-free cells with time for different initial frequencies of plasmid-free cells: $2.5 \times 10^{-3}(\mathrm{O})$, $1 \times 10^{-4},(\square), 1 \times 10^{-6}(\Lambda)$ and $1 \times 10^{-8}(\nabla)$.

speculation is correct. Our results suggested that deletants did not arise due to a growth advantage, since benzoate caused an almost equal inhibition of growth of cells carrying intact or deleted plasmid. It is therefore likely that benzoate induced deletions but we cannot postulate a mechanism for this effect, at present.

Plasmid loss apparently depended on the prior occurrence of deletions. It is possible that plasmid loss was simply a consequence of selection of plasmid-free cells due to their growth advantage over cells containing intact or deleted plasmid, rather than a consequence of disruption of segregation. This necessitates that a proportion of the initial population lacked the plasmid. In our experiments, it was not possible to detect plasmid-free cells amongst the population screened (approximately 400 colonies) prior to exposure to the acids, suggesting a maximum frequency of $2.5 \times 10^{-3}$. The initial inoculum for these experiments was approximately $1 \times 10^{9}$ cells, indicating a minimum frequency of plasmid-free cells of $1 \times 10^{-9}$. Fig. 7 shows the theoretical increase of the frequency of plasmid-free cells during growth with 3 mM-benzoate, which may be compared with the experimental results in Fig. 3. It is evident that plasmid loss, after the initial lag, was far too rapid to be explained simply by the proliferation of plasmid-free cells. Plasmid loss was therefore cooperative, suggesting that segregation of the plasmid was disrupted by benzoate. Disruption of partitioning together with the growth advantage of plasmid-free cells would explain the kinetics of plasmid loss (Seo \& Bailey, 1985).

Partition loci have been described for a variety of low-copy plasmids and are involved in the accurate segregation of plasmid molecules between daughter cells (Sherratt, 1986). Similarly, plasmids can control their copy number by regulating the initiation of replication and preventing multimerization. Nevertheless, plasmids remain dependent upon the host for DNA chain elongation and the spatial organization of partitioning. It is therefore evident that plasmid maintenance depends upon both plasmid- and host-specified mechanisms. It has been observed that plasmids can be lost when the host cell is stressed by a change in the growth environment (Melling et al., 1977; Godwin \& Slater, 1979; Jones et al., 1980; Otto et al., 1982). Such observations suggest that the host can 'override' the variety of plasmid stability determinants elaborated by the plasmid. It is usually difficult to analyse the mechanism by which this occurs, mainly because the changes in growth conditions which have been reported to cause plasmid loss (e.g. change of $\mathrm{pH}$, phosphate limitation) have pleiotropic physiological effects. We observed that lipophilic weak acids induced deletions of TOL plasmid DNA and disrupted the segregation of the deleted plasmid. The deleted plasmid was stably maintained in the absence of 
the acid, indicating that deletions alone did not cause plasmid loss, although they apparently contributed to reduced plasmid stability in the presence of the acid. However, it was evident that the acids additionally induced a change in host cell physiology (growth inhibition). We propose that this physiological change, in combination with the change in plasmid structure, led to a disturbance of the plasmid partitioning mechanism so that plasmid loss was largely hostspecified. Analysis of the nature of growth inhibition by the acids should therefore permit the identification of host-specified determinants of plasmid stability.

The effectiveness of a variety of lipophilic weak acids suggests that their effects were dependent on their lipophilic or acidic nature rather than their structure. Benzoic and acetic acids are known to inhibit bacterial growth and are used as food preservatives. Although the dissociated acids seem to play some part in the toxicity of these compounds, the undissociated acids appear to be more effective in causing growth inhibition and the effect seems to be due to dissipation of the transmembrane $\mathrm{pH}$ gradient (Salmond et al., 1984). We demonstrated that benzoic acid was more effective in inducing plasmid loss than the benzoate anion. However, 5,5dimethyl-oxazolidine-2,4-dione, nigericin, valinomycin and carbonylcyanide $p$-trifluoromethoxyphenylhydrazone (FCCP) did not cause plasmid loss (results not shown), suggesting that the effect of weak acids was unlikely to be due to their effectiveness as uncouplers. The lipophilic nature of the undissociated acids suggests that an additional effect might be disruption of the inner or outer cell membrane. Evidence is accumulating that cell membranes or protein components thereof are involved in plasmid partitioning (Gustafsson et al., 1983; Lancaster et al., 1986). Indeed, butanol is known to disrupt cell membranes and we found that $0 \cdot 1 \%$ butanol also induced deletions and plasmid loss in strain MT15 (results not shown). It is therefore tempting to speculate that lipophilic weak acids disrupted plasmid segregation by interference with membrane structure. However, it is currently difficult to postulate a mechanism by which these acids caused specific deletions of plasmid DNA.

This work was supported by a grant from the SERC Biotechnology Directorate. We wish to thank Miss J. M. Sidebotham for excellent technical assistance and Dr N. H. Mann for helpful suggestions and constructive discussions.

\section{REFERENCES}

Bayley, S. A., Duggleby, C. J., Worsey, M. J., Williams, P. A., HaRdY, K. G. \& Broda, P. (1977). Two modes of loss of the TOL function from Pseudomonas putida mt-2. Molecular and General Genetics 154, 203-204.

Clarke, P. H. \& Laverack, P. D. (1984). Growth characteristics of Pseudomonas strains carrying catabolic plasmids and their cured derivatives. FEMS Microbiology Letters 24, 109-112.

Godwin, D. \& Slater, J. H. (1979). The influence of the growth environment on the stability of a drug resistance plasmid in Escherichia coli K12. Journal of General Microbiology 111, 201-210.

Gustafsson, P., Wolf-Watz, H., Lind, L., JohansSON, K.-E. \& Nordstrom, K. (1983). Binding between the par region of plasmids $\mathrm{R} 1$ and $\mathrm{pSC} 101$ and the outer membrane fraction of the host bacteria. EMBO Journal 2, 27-32.

Jones, I. M., Primrose, S. B., Robinson, A. \& Ellwood, D. C. (1980). Maintenance of some ColE1-type plasmids in chemostat culture. Molecular and General Genetics 180, 579-584.

Keil, H. \& Williams, P. A. (1985). A new class of TOL plasmid deletion mutants in Pseudomonas putida MT15 and their reversion by tandem gene amplification. Journal of General Microbiology 131, 1023-1033.

KeIL, H., Lebens, M. R. \& Williams, P. A. (1985).
TOL plasmid pWW15 contains two non-homologous independently regulated catechol 2,3-oxygenase genes. Journal of Bacteriology 163, 248-255.

Keshavarz, T., Lilly, M. D. \& Clarke, P. H. (1985). Stability of a catabolic plasmid in continuous culture. Journal of General Microbiology 131, 11931203.

Kunz, D. A. \& Chapman, P. J. (1981). Isolation and characterization of spontaneously occurring TOL plasmid mutants of Pseudomonas putida HS1. Journal of Bacteriology 146, 952-964.

Lancaster, M., Prior, S. \& ManN, N. H. (1986). The effect of procaine on the partitioning of plasmid pSC101. FEMS Microbiology Letters 37, 309-312.

Melling, J., Ellwood, D. C. \& Robinson, A. (1977). Survival of R-factor carrying Escherichia coli in mixed cultures in the chemostat. FEMS Microbiology Letters 2, 87-89.

Meulien, P., Downing, R. G. \& Broda, P. (1981). Excision of the $40 \mathrm{~kb}$ segment of the TOL plasmid from Pseudomonas putida $\mathrm{mt}-2$ involves direct repeats. Molecular and General Genetics 184, 97-101.

NakazawA, T. \& YokotA, T. (1973). Benzoate metabolism in Pseudomonas putida (arvilla) mt-2: demonstration of two benzoate pathways. Journal of Bacteriology 115, 262-267.

Otto, R., DE Vos, W. M. \& Gavrieli, J. (1982). 
Plasmid DNA in Streptococcus cremoris $\mathrm{Wg}$ : influence of $\mathrm{pH}$ on selection in chemostats of a variant lacking a protease plasmid. Applied and Environmental Microbiology 43, 1272-1277.

Pickup, R. W. \& Williams, P. A. (1982). Spontaneous deletions in the TOL plasmid pWW20 which give rise to the B3 regulatory mutants of Pseudomonas putida MT20. Journal of General Microbiology 128, 1385-1390.

Pickup, R. W., Lewis, R. J. \& Williams, P. A. (1983). Pseudomonas sp. MT14, a soil isolate which contains two large catabolic plasmids, one a TOL plasmid and one coding for phenylacetate catabolism and mercury resistance. Journal of General Microbiology 129, 153-158.

PIRT, S. J. (1975). Principles of Microbe and Cell Cultivation, p. 5. Oxford: Blackwell Scientific Publications.

SAlmond, C. V., Kroll, R. G. \& Booth, I. R. (1984). The effect of food preservatives on $\mathrm{pH}$ homeostasis in Escherichia coli. Journal of General Microbiology 130, 2845-2850.

SeO, J. H. \& Bailey, J. E. (1985). A segregated model for plasmid content and product synthesis in unstable binary fission recombinant organisms. Biotechnology and Bioengineering 27, 156-165.

SHERRATT, D. (1986). Control of plasmid maintenance. Symposia of the Society for General Microbiology 39, 239-250.

Vishniac, W. \& Santer, M. (1957). The thiobacilli. Bacteriological Reviews 21, 195-213.

WheAtCroft, R. \& Williams, P. A. (1981). Rapid methods for the study of both stable and unstable plasmids in Pseudomonas. Journal of General Microbiology 124, 433-437.

Williams, P. A. \& MurRay, K. (1974). Metabolism of benzoate and the methylbenzoates by Pseudomonas putida (arvilla) mt-2: evidence for the existence of a TOL plasmid. Journal of Bacteriology 120, 416-423. 